\title{
Use of electromyography to detect muscle exhaustion in finishing barrows fed ractopamine $\mathrm{HCl}^{1}$
}

\author{
J. A. Noel,* R. M. Broxterman, $†$ G. M. McCoy, ${ }^{*}$ J. C. Craig, $†$ K. J. Phelps, ${ }^{*}$ D. D. Burnett, ${ }^{*}$ M. A. Vaughn,* \\ T. J. Barstow, $\dagger$ T. G. O’Quinn,* J. C. Woodworth,* J. M. DeRouchey,* T. G. Rozell,* and J. M. Gonzalez*2
}

*Department of Animal Sciences and Industry, and †Department of Kinesiology, Kansas State University, Manhattan 66506

\begin{abstract}
The objectives of this study were to determine the effects of dietary ractopamine $\mathrm{HCl}$ (RAC) on muscle fiber characteristics and electromyography (EMG) measures of finishing barrow exhaustion when barrows were subjected to increased levels of activity. Barrows ( $n=34 ; 92 \pm$ $2 \mathrm{~kg}$ initial BW) were assigned to 1 of 2 treatments: a conventional swine finishing diet containing $0 \mathrm{mg} / \mathrm{kg}$ ractopamine $\mathrm{HCl}(\mathrm{CON})$ or a diet formulated to meet the requirements of finishing barrows fed $10 \mathrm{mg} /$ $\mathrm{kg} \mathrm{RAC} \mathrm{(RAC+).} \mathrm{After} 32 \mathrm{~d}$ on feed, barrows were individually moved around a track at $0.79 \mathrm{~m} / \mathrm{s}$ until subjectively exhausted. Wireless EMG sensors were affixed to the deltoideus (DT), triceps brachii lateral head (TLH), tensor fasciae latae (TFL), and semitendinosus (ST) muscles to measure median power frequency (MdPF) and root mean square (RMS) as indicators of action potential conduction velocity and muscle fiber recruitment, respectively. After harvest, samples of each muscle were collected for fiber type, succinate dehydrogenase (SDH), and capillary density analysis. Speed was not different $(P=0.82)$ between treatments, but RAC + barrows reached subjective exhaustion earlier and covered less distance than CON barrows $(P<0.01)$. There were no treat-
\end{abstract}

ment $\times$ muscle interactions or treatment effects for end-point MdPF values $(P>0.29)$. There was a treatment $\times$ muscle interaction $(P=0.04)$ for end-point RMS values. The RAC diet did not change end-point RMS values in the DT or TLH $(P>0.37)$; however, the diet tended to decrease and increase end-point RMS in the ST and TFL, respectively $(P<0.07)$. There were no treatment $\times$ muscle interactions for fiber type, $\mathrm{SDH}$, or capillary density measures $(P>$ $0.10)$. Muscles of RAC + barrows tended to have less type I fibers and more capillaries per fiber $(P<0.07)$. Type I and IIA fibers of RAC + barrows were larger $(P<0.07)$. Compared with all other muscles, the ST had more $(P<0.01)$ type IIB fibers and larger type I, IIA, and IIX fibers $(P<0.01)$. Type I, IIA, and IIX fibers of the ST also contained less SDH compared with the other muscles $(P<0.01)$. Barrows fed a RAC diet had increased time to subjective exhaustion due to loss of active muscle fibers in the ST, possibly due to fibers being larger and less oxidative in metabolism. Size increases in type I and IIA fibers with no change in oxidative capacity could also contribute to early exhaustion of RAC + barrows. Overall, EMG technology can measure real-time muscle fiber loss to help explain subjective exhaustion in barrows.

Key words: barrow, electromyography, exhaustion, fiber type, ractopamine $\mathrm{HCl}$

\section{INTRODUCTION}

Fatigued pig syndrome has been used to loosely characterize pigs that inordinately suffer from transport stress in spite of having no obvious signs of dis-

\footnotetext{
${ }^{1}$ Contribution number 16-253-J of the Kansas Agricultural Experiment Station, Manhattan, KS 66506.

${ }^{2}$ Corresponding author: johngonz@k-state.edu

Received February 19, 2016.

Accepted March 24, 2016.
} ease or injury (Ritter et al., 2009). Typically, fatigued pigs may recover if rested for 2 to $3 \mathrm{~h}$ after transport (Ritter et al., 2006), but many pigs likely die before they can recover (Hamilton et al., 2004). Ritter et al. 
(2009) estimated fatigued pig syndrome may cause as much as US\$46 million in losses annually. Although there is likely no single cause of this syndrome, use of feed additives designed to increase skeletal muscle growth during finishing may contribute.

Ractopamine $\mathrm{HCl}$ (RAC), a $\beta$-adrenergic agonist fed during the finishing phase of swine production, improved ADG, feed efficiency, and lean muscle growth (Watkins et al., 1990; Moloney et al., 1991). Studies reported RAC increased the rate of fatigue when pigs were roughly handled; however, these studies used indirect measures of blood metabolites as indicators (James et al., 2013; Peterson et al., 2015; Puls et al., 2015). Dietary RAC shifted muscle fiber type from oxidative to glycolytic metabolism (Paulk et al., 2014), but the impact of fiber shifts on fatigue remain unexplored.

Wireless electromyography (EMG) has been used in human physiology to directly measure median power frequency (MdPF) and root mean square (RMS), which serve as indicators of action potential conduction velocity and muscle fiber recruitment, respectively (Broxterman et al., 2014). Fatigue in other livestock species has been measured via EMG (Girsch et al., 1995; Robert et al., 2000; Lee et al., 2013; Rajapaksha and Tucker, 2014), but these studies did not explore the biological characteristics of the muscle responsible for fatigue. Therefore, the objectives of this study were to use a RAC diet feeding model to induce muscle exhaustion in barrows, measure muscle fiber activity via EMG, and relate differences in exhaustion to muscle fiber type characteristic differences.

\section{MATERIALS AND METHODS}

The Kansas State University Institutional Animal Care and Use Committee approved the protocol used in this experiment.

\section{Live Animal Management}

Thirty-four finishing barrows (PIC $337 \times 1050$ [Pig Improvement Co. Hendersonville, TN]; BW $92 \mathrm{~kg} \pm 2$ $\mathrm{kg}$ initial) were housed in an environmentally controlled finishing barn at the Kansas State University Swine Teaching and Research Center (Manhattan, KS). Seven days before beginning the feeding portion of the experiment, barrows were selected from the general population and moved into 7.4- $\mathrm{m}^{2}$ individual pens with slatted floors. Each pen was equipped with a wet/dry feeder that allowed ad libitum access to feed and water. Twentyfour hours before treatment administration, barrows were weighed, stratified by weight, and allocated to 1 of 2 dietary treatments within each stratum. Dietary treatments consisted of a conventional swine finishing diet containing $0 \mathrm{mg} / \mathrm{kg}$ ractopamine $\mathrm{HCl}(\mathbf{C O N})$ or a diet formulated to meet the requirements of finishing barrows fed $10 \mathrm{mg} / \mathrm{kg}$ RAC (RAC+; Paylean; Elanco Animal Health, Greenfield, IN) according to NRC requirements (NRC, 2012). Diets were assayed to contain 8 to $9 \mathrm{mg} / \mathrm{kg}$ (Table 1). The experiment was repeated 3 times ( 2 periods with 10 barrows and 1 period with 14 barrows).

\section{Performance Test}

On d 32 of feeding, barrows were randomly assigned a test order and individually subjected to a performance test. Before each test, the barrow was removed from its pen and restrained, and $15 \mathrm{~mL}$ of blood was collected from the jugular vein into 2 vacutainer tubes containing sodium heparin or sodium fluoride/potassium oxalate (BD Vacutainer; Becton, Dickinson and Company, Franklin Lakes, NJ). Using hair clippers (305 Speed Feed Trim Kit; Laube Co., Inc., Oxnard, CA), the hair covering the deltoideus (DT), triceps brachii lateral head (TLH), tensor fasciae latae (TFL), and semitendinosus (ST) muscles on the left side of the barrow was trimmed. The shaved areas were cleaned with $70 \%$ ethanol and air dried, and wireless EMG (Tringo EMG; Delsys, Inc., Natick, MA) electrodes were affixed to each muscle area so that the 4 contact bars arranged in a $2 \times 2$ orientation were placed perpendicular to the orientation of the muscle fibers. Data were sampled at $1,000 \mathrm{~Hz} / \mathrm{s}$ and stored for later analysis.

Each barrow was walked at an average speed of $0.79 \mathrm{~m} / \mathrm{s}$ around a circular track (30.67 m perimeter) by 3 handlers with sorting boards and paddles until subjective exhaustion was achieved. Subjective exhaustion was determined by the same handler, who was blinded to treatment allocation, for all 34 barrows. Subjective exhaustion was determined as the barrow stopping forward movement (not due to distraction or discomfort), which resulted in human application of pressure to the rump to resume movement, 5 times. If a barrow refused to continue forward movement after $20 \mathrm{~s}$ of encouragement during a single stop, exhaustion was also designated. Time and distance to exhaustion were recorded for each barrow and average speed was calculated based on laps per minute. After each test, the barrow was restrained and 15 $\mathrm{mL}$ of blood was collected as previously described.

\section{Plasma Analysis}

Within 10 min of each blood collection, tubes were centrifuged at $1,115 \times g$ for $10 \mathrm{~min}$ at $4^{\circ} \mathrm{C}$. Plasma was transferred to $15-\mathrm{mL}$ conical tubes, immediately placed on ice, and ultimately frozen at $-80^{\circ} \mathrm{C}$ until analyzed. Plasma glucose and lactate were analyzed using a YSI 2300 STAT Plus Glucose and L-lactate Analyzer (YSI Inc., Yellow Springs, $\mathrm{OH}$ ) with the use of a buffer con- 
Table 1. Diet composition (as-fed basis) ${ }^{1}$

\begin{tabular}{|c|c|c|}
\hline Item & Control & $\overline{\mathrm{RAC}^{2}}$ \\
\hline \multicolumn{3}{|l|}{ Ingredient, \% } \\
\hline Corn & 82.93 & 75.17 \\
\hline Soybean meal & 14.93 & 22.40 \\
\hline Calcium carbonate & 1.00 & 0.98 \\
\hline Monocalcium phosphate & 0.30 & 0.25 \\
\hline Salt & 0.35 & 0.35 \\
\hline L-Lysine $\mathrm{HCl}$ & 0.22 & 0.28 \\
\hline DL-Methionine & - & 0.06 \\
\hline L-Threonine & 0.05 & 0.10 \\
\hline Ractopamine $\mathrm{HCl} 4.95 \mathrm{~g} / \mathrm{kg}$ & - & 0.20 \\
\hline Trace mineral premix ${ }^{3}$ & 0.10 & 0.10 \\
\hline Vitamin premix ${ }^{4}$ & 0.10 & 0.10 \\
\hline Phytase ${ }^{5}$ & 0.01 & 0.01 \\
\hline Total & 100 & 100 \\
\hline \multicolumn{3}{|l|}{ Calculated analysis, $\%$} \\
\hline \multicolumn{3}{|c|}{ Standardized ileal digestible (SID) AA, \% } \\
\hline Lys & 0.72 & 0.95 \\
\hline Ile:Lys & 66 & 63 \\
\hline Leu:Lys & 162 & 141 \\
\hline Met:Lys & 30 & 33 \\
\hline Met and Cys:Lys & 59 & 59 \\
\hline Thr:Lys & 65 & 65 \\
\hline Trp:Lys & 18.0 & 18.0 \\
\hline Val:Lys & 76 & 70 \\
\hline Total lysine, $\%$ & 0.82 & 1.07 \\
\hline $\mathrm{ME}, \mathrm{Mcal} / \mathrm{kg}$ & 3.32 & 3.31 \\
\hline SID Lysine:ME, g/Mcal & 2.17 & 2.87 \\
\hline $\mathrm{CP}, \%$ & 14.2 & 17.3 \\
\hline $\mathrm{Ca}, \%$ & 0.52 & 0.52 \\
\hline $\mathrm{P}, \%$ & 0.39 & 0.41 \\
\hline Available P, \% & 0.22 & 0.22 \\
\hline
\end{tabular}

${ }^{1}$ Diets were fed in meal form for the duration of the experiment.

${ }^{2} \mathrm{RAC}=$ ractopamine $\mathrm{HCl}$ (Paylean; Elanco Animal Health, Greenfield, IN; fed during the final $35 \mathrm{~d}$ of feeding).

${ }^{3}$ Trace mineral premix provided $16.53 \mathrm{mg} \mathrm{Mn}, 55.06 \mathrm{mg} \mathrm{Fe}, 55.06 \mathrm{mg} \mathrm{Zn}$, $8.25 \mathrm{mg} \mathrm{CU}, 0.15 \mathrm{mg}$ I, and $0.15 \mathrm{mg}$ Se per kilogram of the complete diet.

${ }^{4}$ Vitamin premix provided 3,307 IU vitamin A, 413 IU vitamin $\mathrm{D}_{3}, 13 \mathrm{IU}$ vitamin $\mathrm{E}, 1.32 \mathrm{mg}$ vitamin $\mathrm{K}, 11.6 \mu \mathrm{g}$ vitamin $\mathrm{B}_{12}, 14.9 \mathrm{mg}$ niacin, $8.27 \mathrm{mg}$ pantothenic acid, and $2.48 \mathrm{mg}$ riboflavin per kilogram of the complete diet

${ }^{5}$ HiPhos 2700 (DSM Nutritional Products, Inc., Parsippany, NJ; provided 406.31 phytase units $/ \mathrm{kg}$ and an estimated release of $0.10 \%$ available $\mathrm{P}$ ).

taining disodium phosphate, monosodium phosphate, sodium benzoate, disodium EDTA, sodium chloride, and gentamicin sulfate (part number 2537; YSI Inc.). Glucose analysis was conducted using glucose membranes (part number 2365; YSI Inc.) and $2 \mathrm{~g} / \mathrm{L}$ glucose standard (part number 2355; YSI Inc.), and lactate analysis used 1-lactate membranes (part number 2329; YSI, Inc.) and 30 mmol/L 1-lactate standard (part number 1530; YSI Inc.). Glutamate and glutamine were analyzed using an YSI 2700 SELECT Analyzer (YSI Inc.) and the same buffer described above. Glutamate membranes (part number 2754; YSI Inc.), $5 \mathrm{mmol} / \mathrm{L}$ glutamate standard (part number 2755; YSI Inc.), glutamine membranes (part number
2735; YSI Inc.), and $5 \mathrm{mmol} / \mathrm{L}$ glutamine standard (part number 2736; YSI Inc.) were used in the analysis.

\section{Electromyography Analysis}

The methods of Broxterman et al. (2014) were followed with modifications for EMG analysis. Using a custom computer program in MATLAB Student R2011a (MathWorks, Inc., Natick, MA), raw EMG data were processed for each electrical burst corresponding with a muscle contraction by using a band-pass filter (13-400 $\mathrm{Hz}$ ). The EMG frequency and amplitude characteristics were derived as MdPF and RMS, respectively. Data were averaged every $5 \mathrm{~s}$ during the performance test of each barrow. The MdPF and RMS values of each barrow were normalized to the average of all values of the individual barrow's own performance test, which is commonly done in human performance literature (Murray et al., 1985; Hunter et al., 2014). This average was assigned the value of $100 \%$ and denoted as the normalization value. Subsequent 5 -s increments were divided by the normalization value and multiplied by 100 to yield a percentage of the MdPF or RMS normalization value. The percentages of the last $15 \mathrm{~s}$ before subjective exhaustion was reached by the barrow were averaged and used for statistical analysis as end-point MdPF and RMS values.

\section{Harvest, Sample Collection, Immunohistochemistry, and Histology}

After a 3-d rest period (35 d of feeding), barrows were transported to the Kansas State University Meats Laboratory (Manhattan, KS) for harvest under federal inspection. After chilling for $24 \mathrm{~h}$ postmortem, carcass measurements were taken by trained university personnel. Marbling and color attributes were evaluated according to the National Pork Producers Council Pork Quality Standards (NPPC, 1999). One, $2.54 \mathrm{~cm}$ cores of the DT, TLH, TFL, and ST were taken from the left side of each carcass at the approximate EMG locations for muscle fiber type, succinate dehydrogenase (SDH), and capillary density analysis.

A $1-\mathrm{cm}^{2}$ portion of each core was embedded in tissue embedding media (Fisher Scientific, Pittsburgh, PA), cooled with supercooled isopentane, and stored at $-80^{\circ} \mathrm{C}$ until analysis. Two cryosections per slide, $0.5 \mathrm{~mm}$ apart, for each muscle sample were collected on 3 slides for fiber type ( $5 \mu \mathrm{m}$ thick), capillary density analysis ( $5 \mu \mathrm{m}$ thick), and SDH analysis ( $20 \mu \mathrm{m}$ thick). All cryosections were collected on positively charged slides (Diamond White Glass; Globe Scientific Inc., Paramus, NJ).

The methods of Paulk et al. (2014) were followed for fiber type immunohistochemistry with modifications. Cryosections were incubated in 5\% horse serum and 
0.2\% TritonX-100 in PBS for 30 min to block all nonspecific binding sites. Cryosections were incubated for $16 \mathrm{~h}$ at $4^{\circ} \mathrm{C}$ with a primary antibody solution consisting of blocking solution and 1:500 $\alpha$-dystrophin (Thermo Scientific, Waltham, MA); 1:10 supernatant myosin heavy chain, slow, IgG2b (BA-D5; Developmental Studies Hybridoma Bank, University of Iowa, Iowa City, IA); 1:10 supernatant myosin heavy chain, type IIA, IgGl (SC71; Developmental Studies Hybridoma Bank); and 1:10 supernatant myosin heavy chain, type IIB, IgM (BF-F3; Developmental Studies Hybridoma Bank). Following incubation, cryosections were washed 3 times for 5 min with PBS and incubated for 30 min with secondary antibodies in blocking solution containing 1:1,000 Alexa-Flour 488 Goat anti-mouse IgM (Life Technologies, Carlsbad, CA) for BF-F3, 1:1,000 Alexa-Flour 594 goat anti-mouse IgG1 (Life Technologies) for SC-71, 1:1,000 AlexaFlour 633 goat anti-mouse $\operatorname{IgG}_{2 \mathrm{~b}}$ (Life Technologies) for BAD-5, 1:1,000 Alexa-Flour 594 goat-anti-rabbit heavy and light chains (Life Technologies) for $\alpha$-dystrophin, 1:1,000 Alexa-Flour 488 goat-anti-rabbit heavy and light chains (Life Technologies) for $\alpha$-dystrophin, and 1:1,000 Hoechst Dye 33342 (Life Technologies). After washing in PBS 3 times for $5 \mathrm{~min}, 5 \mu \mathrm{L}$ of 9:1 glycerol in PBS was placed on each cryosection and they were then coverslipped for imaging.

Slides with cryosections for SDH staining were incubated at $37^{\circ} \mathrm{C}$ for $1 \mathrm{~h}$ in a prewarmed incubation solution containing $50 \%$ nitro blue tetrazolium solution ( $1 \%$ nitro blue tetrazolium in Milli-Q [MQ] water), 25\% phosphate buffer $(20 \%$ potassium phosphate monohydrate and $11 \%$ disodium hydrogen phosphate in MQ water), and $25 \%$ sodium succinate solution $(2.7 \%$ sodium succinate dibasic hexahydrate in MQ water). After washing in MQ water 3 times for 1 min each, $5 \mu \mathrm{L}$ of 9:1 glycerol in PBS was placed on each cryosection and they were coverslipped for imaging.

Cryosections for capillary density were blocked as described above. Cryosections were then incubated for $1 \mathrm{~h}$ in a primary antibody solution containing blocking solution and 1:50 plateletendothelial cell adhesion molecule-1 mouse monoclonal IgG2a (Santa Cruz Biotechnology Inc., Dallas, TX) and 1:500 $\alpha$-dystrophin (Thermo Scientific). Cryosections were washed 3 times for $5 \mathrm{~min}$ with PBS and incubated for $30 \mathrm{~min}$ with secondary antibodies in blocking solution containing 1:1,000 Alexa-Flour 594 goat-anti-mouse $\operatorname{IgG}$ heavy and light chains (Life Technologies) for PECAM-1 and 1:1,000 Alexa-Flour 488 goat-anti-rabbit heavy and light chains (Life Technologies) for $\alpha$-dystrophin. After washing in PBS 3 times for 5 min, cryosections were covered with $5 \mu \mathrm{L}$ of 9:1 glycerol and coverslipped for imaging.

All cryosections were imaged at $10 \mathrm{x}$ magnification with a Nikon Elipse TI-U inverted microscope
(Nikon Instruments Inc., Melville, NY). Muscle fiber type and capillary photomicrographs were taken with a Nikon DS-QiMC digital camera (Nikon Instruments Inc.) and SDH photomicrographs were captured with Nikon DS-Fi1 color digital camera (Nikon Instruments Inc.). White light intensity was kept constant for SDH photomicrographs. All analysis was conducted using NIS-Elements Imaging software (Basic Research, 3.3; Nikon Instruments Inc.). An average of 500 muscle fibers were analyzed for myosin heavy chain isoform distribution and fiber cross-sectional area (CSA). Fibers that stained exclusively positive for BAD-5, SC-71, and BF-F3 were labeled type I, type IIA, and IIB, respectively. Fibers that stained positive for both SC-71 and B-FF3 were labeled as type IIX fibers (Fig. 1; Paulk et al., 2014). Cross-sectional area of muscle fibers was determined as the area within the dystrophin border. Capillary density was determined by dividing the total number of capillaries by the total number of muscle fibers within a photomicrograph to yield a ratio. A minimum of 500 fibers and their associated capillaries were counted with all fibers counted in a photomicrograph. To determine SDH intensity, a minimum of 200 fibers were identified by type through immunohistochemistry, and the mean intensity of the SDH stain was determined by the software. A value of 0 indicated black (most intense) staining, whereas a value of 250 indicated white (least intense) staining.

\section{Statistics}

All analyses were performed using animal as the experimental unit and experimental period as block. Finishing performance, carcass, and performance test data were analyzed as a randomized complete block design. Treatment served as the fixed effect and block served as the random effects. Blood measures were analyzed as a randomized complete block design with repeated measures. Fixed and random effects were the same as described above and time served as the repeated measure, with animal as the subject and compound symmetry as the covariance structure. Muscle immunohistochemistry and histochemistry and EMG data were analyzed as a split-plot design. The whole plot consisted of animal and muscle within animal served as the subplot. Fixed effects included treatment, muscle, and their interaction, and random effects were animal $\times$ treatment and block. All models were analyzed using the MIXED procedure of SAS 9.3 (SAS Inst. Inc., Cary, NC). Pairwise comparisons between the least squares means of the factor level comparisons were computed using the PDIFF option of the LSMEANS statement. Statistical significance was determined at $P \leq 0.05$ and tendencies were determined at $0.05>P \leq 0.10$. 


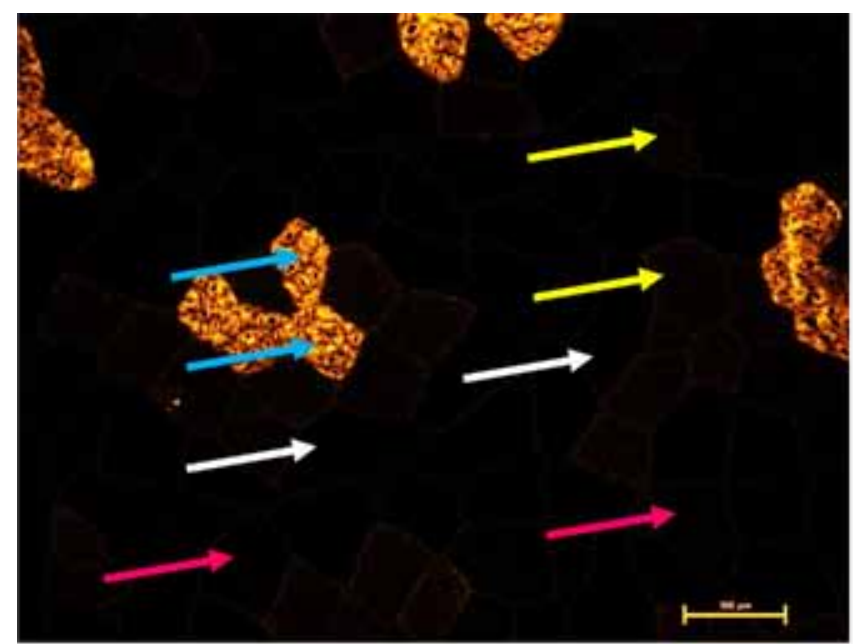

BA-D5 (Type 1)

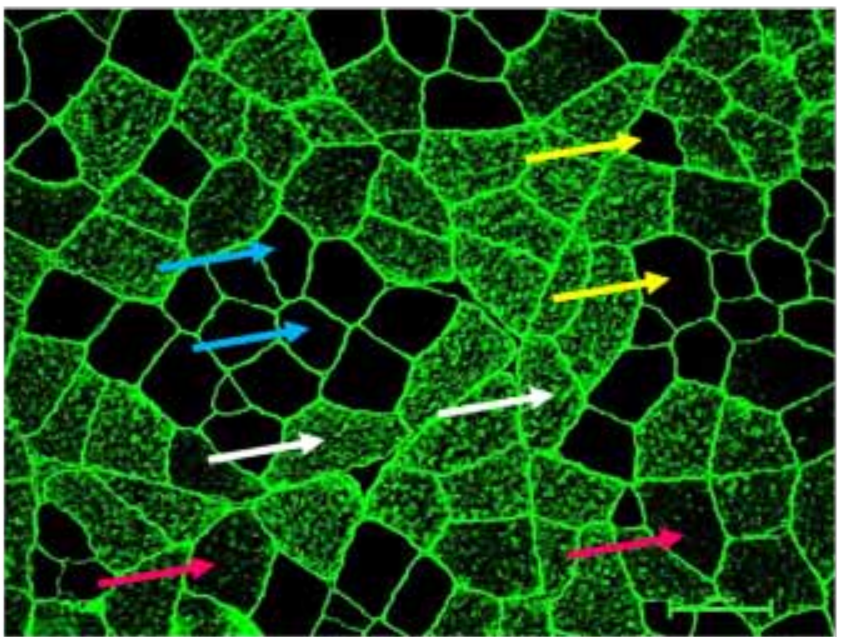

BF-F3 (Type IIB)

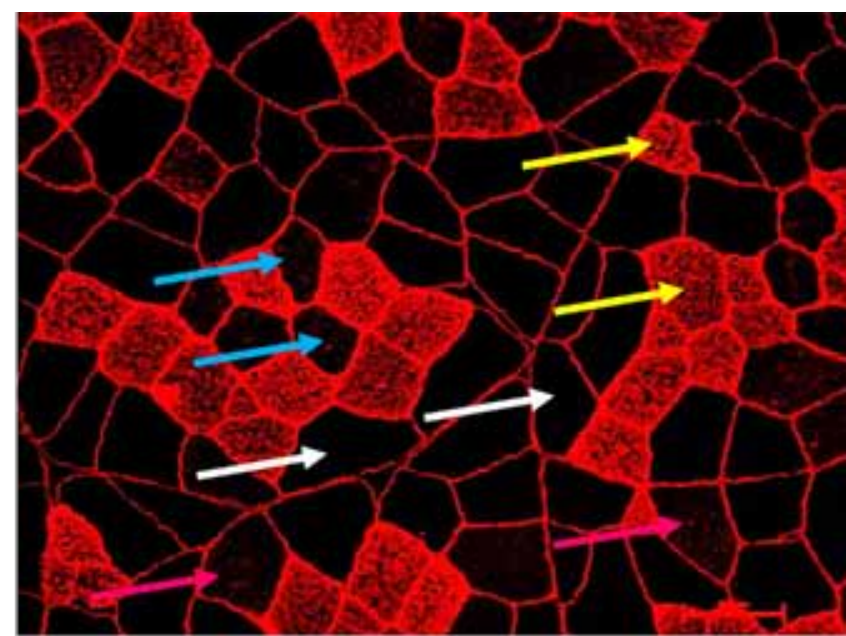

SC-71 (Type IIA)

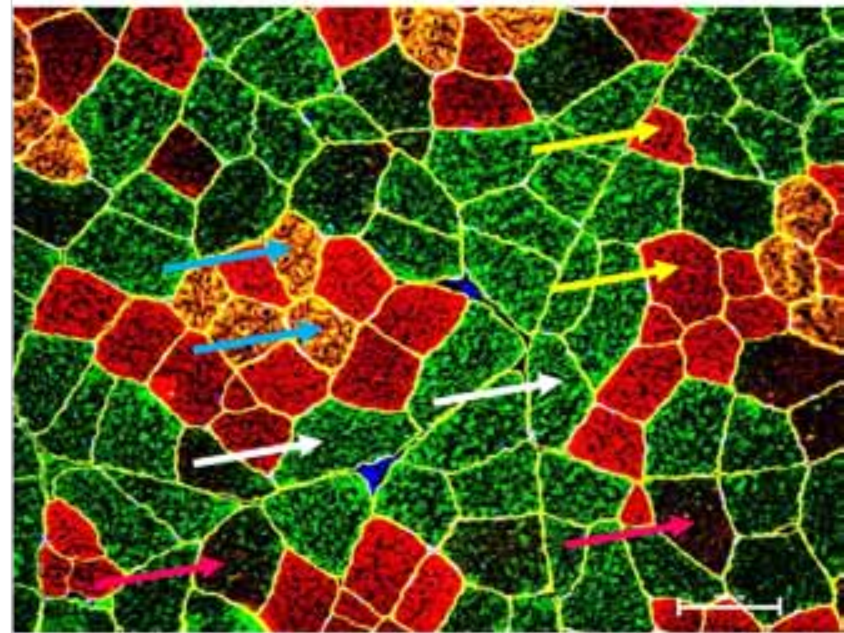

Merged image

Figure 1. Representative photomicrographs of immunohistological fiber type staining pattern of the porcine triceps lateral head muscle. Fibers that stained positive for the BA-D5 (Developmental Studies Hybridoma Bank, University of Iowa, Iowa City, IA) antibody were categorized as type I fibers (blue arrows), fibers that stained positive only for the SC-71 (Developmental Studies Hybridoma Bank) antibody were categorized as type IIA fibers (yellow arrows), fibers that stained positive only for the BF-F3 (Developmental Studies Hybridoma Bank) antibody were categorized as type IIB fibers (white arrows), and fibers that stained positive for both SC-71 and BF-F3 were categorized as type IIX fibers (pink arrows; Paulk et al., 2014). Scale bars $=100 \mu \mathrm{m}$.

\section{RESULTS}

\section{Growth Performance and Carcass Characteristics}

Finishing performance and carcass measurements are presented in Table 2. Barrows' initial BW, final $\mathrm{BW}$, and $\mathrm{ADG}$ were not different between treatment groups $(P>0.15)$. Barrows from the $\mathrm{RAC}+$ treatment had reduced $(P=0.03)$ ADFI compared with $\mathrm{CON}$ barrows, which resulted in RAC + barrows possessing greater $(P<0.01) \mathrm{G}: \mathrm{F}$. Dietary treatment did not affect $\mathrm{HCW}$, dressing percent, and all s.c. fat measurements $(P>0.11)$. Loin eye area (LEA) and color were not affected by dietary treatment $(P>0.14)$; however, there was less $(P<0.01)$ marbling in the loins of RAC + barrows compared with loins from $\mathrm{CON}$ barrows.

\section{Performance Test and Electromyography Analysis}

There was no difference $(P=0.82)$ in the speed at which barrows moved around the track; however, barrows from the RAC + treatment reached subjective exhaustion earlier and covered less distance than CON barrows $(P<0.01$; Table 3$)$. There were no treatment $\times$ muscle interaction, treatment, or muscle effects for end-point MdPF values $(P>0.42$; Fig. $2 \mathrm{a})$. There was a treatment $\times$ muscle interaction $(P=0.04)$ for endpoint RMS values (Fig. 2b). Dietary treatment did not affect end-point RMS values of the DT or TLH $(P>$ $0.37)$, but RAC + barrows tended to have decreased $(P$ $=0.06)$ end-point RMS values in the ST and tended to have increased $(P=0.07)$ end-point RMS values in the TFL compared with CON barrows. There were no treatment effects or muscle effects for end-point RMS values $(P>0.15)$. 
Table 2. Growth and carcass characteristics of barrows fed a conventional swine finishing diet containing $0 \mathrm{mg} / \mathrm{kg}$ ractopamine $\mathrm{HCl}(\mathrm{CON})$ or a diet formulated to meet the requirements of finishing barrows fed $10 \mathrm{mg} / \mathrm{kg} \mathrm{RAC}^{1}(\mathrm{RAC}+)$ for $35 \mathrm{~d}$

\begin{tabular}{|c|c|c|c|c|}
\hline \multirow[b]{2}{*}{ Item } & \multicolumn{2}{|c|}{ Treatment } & \multirow[b]{2}{*}{ SEM } & \multirow[b]{2}{*}{$P$-value } \\
\hline & $\mathrm{CON}$ & $\mathrm{RAC}+$ & & \\
\hline \multicolumn{5}{|l|}{ Finishing performance } \\
\hline Initial BW, kg & 92.44 & 91.84 & 2.18 & 0.80 \\
\hline Final BW, kg & 139.36 & 141.43 & 5.80 & 0.50 \\
\hline $\mathrm{ADG}, \mathrm{kg}$ & 1.18 & 1.26 & 0.04 & 0.15 \\
\hline ADFI, $\mathrm{kg}$ & 3.82 & 3.47 & 0.14 & 0.03 \\
\hline G:F & 0.315 & 0.365 & 0.016 & $<0.01$ \\
\hline \multicolumn{5}{|l|}{ Carcass characteristics } \\
\hline $\mathrm{HCW}, \mathrm{kg}$ & 108.56 & 107.45 & 6.22 & 0.72 \\
\hline Dressing, $\%$ & 77.69 & 75.90 & 1.64 & 0.33 \\
\hline First rib s.c. fat, cm & 3.95 & 3.71 & 0.27 & 0.24 \\
\hline Tenth rib s.c. fat, cm & 2.50 & 2.26 & 0.18 & 0.11 \\
\hline Last rib s.c. fat, $\mathrm{cm}$ & 2.59 & 2.66 & 0.17 & 0.68 \\
\hline Last lumbar s.c. fat, cm & 2.07 & 2.18 & 0.10 & 0.45 \\
\hline Loin eye area, $\mathrm{cm}^{2}$ & 60.18 & 62.68 & 1.26 & 0.27 \\
\hline Color $^{2}$ & 2.60 & 2.30 & 0.15 & 0.14 \\
\hline Marbling $^{3}$ & 2.00 & 1.47 & 0.13 & $<0.01$ \\
\hline
\end{tabular}

${ }^{1} 10 \mathrm{mg} / \mathrm{kg}$ of ractopamine $\mathrm{HCl}$ (Paylean; Elanco Animal Health, Greenfield, IN; fed during the final $35 \mathrm{~d}$ of feeding).

${ }^{2}$ National Pork Producers Council (1999) pork color standards: $1=$ lightest and $6=$ darkest.

${ }^{3}$ National Pork Producers Council (1999) pork marbling standards: $1=$ no marbling and $10=$ high marbling.

\section{Plasma Analysis}

There were no treatment $\times$ time interactions for plasma lactate, glucose, glutamate, and glutamine values $(P>0.16$; Table 3$)$. There were no treatment effects on circulating lactate, glutamine, or glutamate $(P>0.39)$; however, there was a tendency for the $\mathrm{CON}$ barrows to have elevated $(P=0.09)$ glucose compared with RAC + barrows. There were time effects on all plasma measurements with greater lactate, glucose, and glutamate circulating after the performance test for all barrows $(P<$ $0.01)$, whereas glutamine was reduced $(P<0.01)$.

\section{Immunohistochemistry and Histology}

Treatment, muscle, and their interaction effects on immunohistological and histological measurements were analyzed within each muscle fiber isoform, except for capillary density, which was analyzed over all fibers (Table 4). There were no treatment $\times$ muscle interactions for the percentage of each fiber type $(P>0.12)$, except a tendency $(P=0.10)$ for type IIA percentage. Within DT, TLH, and ST muscles, type IIA fiber percentage was not affected by dietary treatment $(P>0.39)$; however, within the TFL, RAC + barrows had a greater $(P=0.02)$ percent- age of type IIA fibers than CON barrows. Over all muscles, treatment did not affect the percentage of type IIA, IIX, and IIB fibers $(P>0.13)$, but CON barrows tended to have more $(P=0.07)$ type I fibers than $\mathrm{RAC}+$ barrows. There were muscle effects on type I and IIB muscle fibers $(P<0.01)$. The DT had more type I fibers than all other muscles $(P<0.04)$, the TLH had more type I fibers than the ST and TFL $(P<0.01)$, and there was a tendency for the TFL to have more $(P=0.09)$ type I fibers than the ST. Type IIA and IIX fiber percentage tended to be affected by muscle $(P<0.10)$. The DT and TLH had a greater percentage of type IIA fibers than the ST $(P<0.03)$, whereas there were no differences between the other muscles $(P$ $>0.15)$. There were more $(P<0.01)$ type IIX fibers in the DT compared with the ST, the DT tended to have more $(P=0.10)$ type IIX fibers than the TFL, and there were no differences between the other muscles $(P>0.17)$. There were more type IIB fibers in the ST compared with the other muscles $(P<0.01)$, the TFL contained more type IIB fibers than the DT and TLH $(P<0.01)$, and the TLH had more $(P=0.01)$ type IIB fibers than the DT.

There were no treatment $\times$ muscle interactions for the CSA of any fiber type $(P>0.36)$. Over all muscles, treatment did not affect the CSA of type IIX and IIB fibers $(P>0.11)$, but RAC+ barrows tended to have larger $(P=0.07)$ type I fibers and larger $(P=0.03)$ type IIA fibers compared with CON barrows. There were muscle effects on the CSA of type I, IIA, and IIX fibers $(P<0.01)$ but no effect $(P=0.67)$ on type IIB fibers. Within type I fibers, the ST had larger fibers than all other muscles $(P<0.01)$, the DT and TLH had larger fibers than the TFL $(P<0.01)$, and there was no size difference between the DT and TLH $(P=0.70)$. There were larger type IIA fibers in the ST compared with the other muscles $(P<0.01)$, the TLH tended to have larger type IIA fibers than the TFL $(P=0.08)$, and there were no differences between the other muscles $(P>0.33)$. Within type IIX fibers, the ST had larger fibers compared with all other muscles $(P<0.01)$ and there were no differences between the other muscles $(P>0.13)$.

There were no treatment $\times$ muscle interactions for the SDH intensity for all fiber types $(P>0.21)$. Across all muscles, there were no treatment effects on SDH intensity $(P>0.21)$. There were muscle effects for SDH intensity within type I, IIA, and IIX fibers $(P<0.01)$, with no effect for type IIB fibers $(P=0.35)$. The ST had less intense SDH staining of the type I fibers compared with all other muscles $(P<0.01)$, there was a tendency for the TFL to have less $(P=0.10)$ SDH staining intensity than the DT for type I fibers, and there were no differences between the other muscles $(P>0.15)$. Within type IIA and IIX fibers, the ST had least intense SDH staining than the other muscles $(P<0.01)$, but there were no differences between the other muscles 
Table 3. Performance test and blood parameters of barrows fed a conventional swine finishing diet containing 0 $\mathrm{mg} / \mathrm{kg}$ ractopamine $\mathrm{HCl}(\mathrm{CON})$ or a diet formulated to meet the requirements of finishing barrows fed $10 \mathrm{mg} / \mathrm{kg}$ $\mathrm{RAC}^{1}(\mathrm{RAC}+)$ for $32 \mathrm{~d}$

\begin{tabular}{|c|c|c|c|c|c|c|}
\hline \multirow[b]{2}{*}{ Item } & \multicolumn{2}{|c|}{ Treatment $^{1}$} & \multirow[b]{2}{*}{ SEM } & \multicolumn{3}{|c|}{$P$-value } \\
\hline & $\mathrm{CON}$ & $\mathrm{RAC}+$ & & Treatment & Time & Treatment $\times$ time \\
\hline \multicolumn{7}{|l|}{$\overline{\text { Performance test }{ }^{2}}$} \\
\hline Average speed, $\mathrm{m} / \mathrm{s}$ & 0.90 & 0.88 & 0.42 & 0.82 & - & - \\
\hline Time to exhaustion, $\mathrm{s}$ & 395.57 & 282.40 & 32.87 & $<0.01$ & - & - \\
\hline Distance to exhaustion, $\mathrm{m}$ & 563.76 & 372.53 & 66.01 & $<0.01$ & - & - \\
\hline \multicolumn{7}{|l|}{ Blood parameter, $\mathrm{mmol} / \mathrm{L}$} \\
\hline Plasma glucose & & & 0.23 & 0.09 & $<0.01$ & 0.16 \\
\hline Before & 4.43 & 3.33 & & & & \\
\hline After & 4.46 & 3.88 & & & & \\
\hline Plasma lactate & & & 1.13 & 0.39 & $<0.01$ & 0.84 \\
\hline Before & 3.58 & 4.38 & & & & \\
\hline After & 8.99 & 10.05 & & & & \\
\hline Plasma glutamate & & & 0.01 & 0.63 & $<0.01$ & 0.86 \\
\hline Before & 0.09 & 0.08 & & & & \\
\hline After & 0.13 & 0.13 & & & & \\
\hline Plasma glutamine & & & 0.16 & 0.63 & $<0.01$ & 0.16 \\
\hline Before & 0.42 & 0.42 & & & & \\
\hline After & 0.38 & 0.37 & & & & \\
\hline
\end{tabular}

${ }^{1} 10 \mathrm{mg} / \mathrm{kg}$ of ractopamine $\mathrm{HCl}$ (Paylean; Elanco Animal Health, Greenfield, IN; fed during the final $35 \mathrm{~d}$ of feeding).

${ }^{2}$ Barrows were removed from pens and individually at $0.79 \mathrm{~m} / \mathrm{s}$ walked around a $30-\mathrm{m}$ track until subjective exhaustion occurred. Exhaustion was determined as the barrow stopping forward movement (not due to distraction or fear), which resulted in human application of pressure to the rump to resume movement, 5 times. If a barrow refused to continue after $20 \mathrm{~s}$ of encouragement, exhaustion was also designated.

$(P>0.41)$. There were no treatment $\times$ muscle interactions or muscle effects for capillary density $(P>0.17)$; however, the RAC+ barrows had more $(P=0.04)$ capillaries per fiber compared with $\mathrm{CON}$ barrows.

\section{DISCUSSION}

\section{Growth Performance and Carcass Characteristics}

Swine producers commonly feed RAC during the final days of finishing because of the positive effects the compound elicits on finishing pig performance and carcass characteristics. In the current study, a RAC diet fed during the final $35 \mathrm{~d}$ of feeding did not affect ADG but did decrease ADFI by $9 \%$ and increased G:F by $16 \%$. Although barrows were individually fed in the current study, groups of pigs were fed in the majority of RAC studies, and differences in study design could be the reason for variable responses between studies (Armstrong et al., 2004; Carr et al., 2005; Paulk et al., 2014). Carr et al. (2005) reported that RAC-fed barrows had increases of $16 \%$ in $\mathrm{ADG}$ and $19 \%$ in G:F but no differences in ADFI. Using barrows and gilts raised at the same farm as the current study, Paulk et al. (2015) reported RAC fed during the final $35 \mathrm{~d}$ of feeding increased ADG by $11 \%$, reduced ADFI by $6 \%$, and increased G:F by $17 \%$. In contrast to these studies, Armstrong et al. (2004) reported that RAC fed to barrows did not influence ADG or ADFI, and Stites et al. (1991) showed that regardless of RAC level in the feed, ADFI was not affected. Overall, significant finishing performance results of the current study are similar to published literature.

Because RAC is a repartitioning agent that directs nutrients away from adipose growth and toward muscle growth, carcasses commonly exhibit more muscle and less fat. Crome et al. (1996) demonstrated that increasing the concentration of RAC in the diet resulted in a linear LEA increase and a linear decrease in first rib, 10th rib, and last lumbar backfat thicknesses. Paulk et al. (2015) reported increases in HCW of $3 \%$ and a $6 \%$ increase of loin depth and a corresponding $16 \%$ decrease in backfat depth when pigs were exposed to the same RAC feeding regimen as the current study. Burnett et al. (2016) showed that $10 \mathrm{mg} / \mathrm{kg}$ RAC tended to increase HCW by $3 \%$, increased LEA by $10 \%$, but only tended to decrease 10th and last rib backfat. In the current study, all carcass measures were unaffected by a RAC diet except that marbling score was reduced $27 \%$ in RAC + barrows. In agreement, Carr et al. (2005) found that RAC did not affect all s.c. backfat measures and Main et al. (2009) reported that $10 \mathrm{mg} / \mathrm{kg}$ RAC did not affect loin depth. Apple et al. (2008) reported that RAC increased marbling, whereas other studies demonstrate RAC does not affect marbling (Crome et al., 1996; Carr et al., 2005; Bohrer et al., 2013); however, Armstrong et al. (2004) found that RAC decreased the amount of 
a)
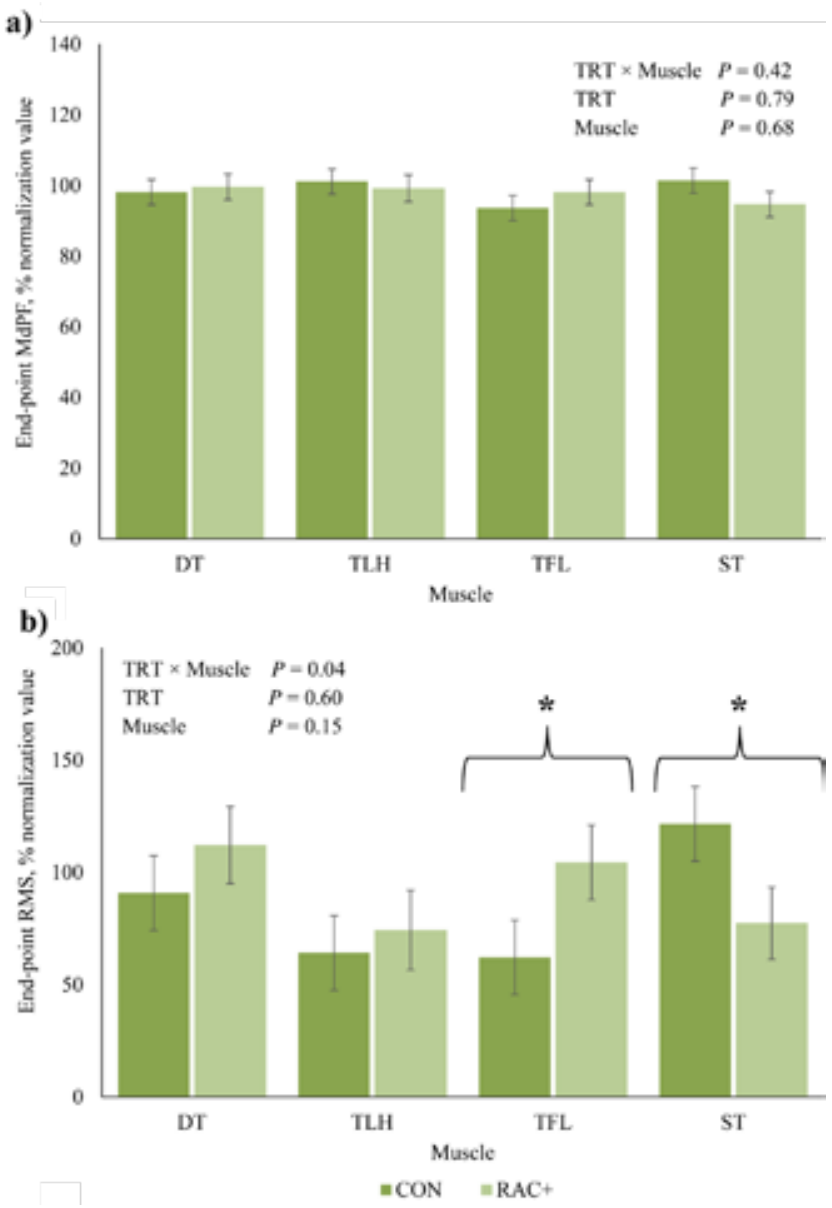

Figure 2. Electromyography (EMG) end-point a) median power frequency (MdPF) and b) root mean square (RMS) values of 4 muscles of pigs subjected to a performance test following $32 \mathrm{~d}$ of feeding a conventional swine finishing diet containing $0 \mathrm{mg} / \mathrm{kg}$ ractopamine $\mathrm{HCl}$ (CON; Paylean; Elanco Animal Health, Greenfield, IN) or a diet formulated to meet the requirements of finishing barrows fed $10 \mathrm{mg} / \mathrm{kg} \mathrm{RAC}(\mathrm{RAC}+)$. Barrows were removed from pens and EMG sensors were attached to the deltoideus (DT), triceps brachii lateral head (TLH), tensor fasciae latae (TFL), and the semitendinosus (ST) muscles. Barrows were individually, at $0.79 \mathrm{~m} / \mathrm{s}$ walked around a 30-m track until subjective exhaustion occurred. Exhaustion was determined as the barrow stopping forward movement (not due to distraction or fear), which resulted in human application of pressure to the rump to resume movement, 5 times. If a barrow refused to continue after $20 \mathrm{~s}$ of encouragement, exhaustion was also designated. Data were averaged every $5 \mathrm{~s}$ during the performance test of each barrow. The MdPF and RMS values of each barrow were normalized to the average of all values of the individual barrow's own performance test, which is commonly done human performance literature (Murray et al., 1985; Hunter et al., 2014). This average was assigned the value of $100 \%$ and denoted as the normalization value. Subsequent $5 \mathrm{~s}$ increments were divided by the normalization value and multiplied by 100 to yield a percentage of the MdPF or RMS normalization value. The percentages of the last $15 \mathrm{~s}$ before subjective exhaustion was reached by the barrow were averaged and used for statistical analysis as end-point MdPF and RMS values. *Mean tend to differ within muscle $(P<0.07)$. TRT $=$ treatment.

marbling. Therefore, these data would indicate the adipose response to a RAC diet is variable between depots. Overall, the lack of significant dietary RAC carcass responses in the current study differs from the majority of the literature. These results may be due to the reduced animal numbers used in the study, as carcass effects were not what the study was designed to detect.

\section{Performance Test}

Previously, pigs fed RAC were categorized as being difficult to handle. Rocha et al. (2013) reported RAC barrows required more physical contact to move during handling and transportation. Additionally, MarchantForde et al. (2003) found pigs fed RAC took longer to voluntarily exit pens during weekly weight measurements, thus making them more difficult to handle. A handful of studies exist that examined the effects of rough handling and dietary RAC on exhaustion. James et al. (2013) concluded pigs fed $20 \mathrm{mg} / \mathrm{kg}$ RAC (2-fold the current label directions) are more prone to stress, as indicated by elevated rectal temperature, decreased blood $\mathrm{pH}$, and increased lactate dehydrogenase concentration, when aggressively handled. Recently, based on a subjective handling scale, Puls et al. (2015) reported pigs fed RAC tended to be harder to handle and of the pigs that did not finish the last $100 \mathrm{~m}$ of a transportation simulation course, pigs fed RAC walked a 7\% shorter distance compared with pigs not fed RAC. Conversely, in another study where the same transportation simulation model was used, Peterson et al. (2015) found that pigs subjected to different levels of RAC and handling intensity did not display diverse fatigability characteristics, such as open-mouth breathing, skin discoloration, muscle tremors, and vocalization. In the current study, RAC + barrows undertook ambulatory movement for almost 2 min less and a $200 \mathrm{~m}$ shorter distance compared with CON barrows. Importantly, these findings were not due to the speed at which the pigs walked; therefore, differences may be due muscle physiological changes induced by the RAC diet.

\section{Plasma Glucose, Lactate, Glutamate, and Glutamine}

Blood parameters have been used as indirect measures of muscle fatigue in human and livestock physical activity research. In humans, plasma glucose levels rise with exercise due to increased hepatic glucose production to meet the amplified demand of glucose uptake by active muscle fibers (Kjäer, 1988). Plasma lactate concentrations are elevated with increasing levels of exercise after the lactate threshold is reached (Svedahl and MacIntosh, 2003) and will precipitously increase until exhaustion if exercise is sufficiently intense (Poole et al., 1988). Increased glutamate and decreased plasma glutamine after prolonged exercise in humans are often indicators of muscle damage (Keast et al., 1995; Walsh et al., 1998; Leibowitz et al., 2012). Each blood plasma parameter in the current study changed after performance testing where circulating glucose $(23 \%)$, lactate (139\%), and glutamate (51\%) were elevated and glutamine $(11 \%)$ was depressed. This would indicate that glucose levels were increased to meet the demand for 
Table 4. Muscle fiber characteristics of 4 muscles in barrows fed a conventional swine finishing diet containing $0 \mathrm{mg} / \mathrm{kg}$ ractopamine $\mathrm{HCl}(\mathrm{CON})$ or a diet formulated to meet the requirements of finishing barrows fed $10 \mathrm{mg} /$ $\operatorname{kg~RAC}{ }^{1}(\mathrm{RAC}+)$ for $35 \mathrm{~d}$

\begin{tabular}{|c|c|c|c|c|c|c|c|c|c|c|c|c|}
\hline \multirow[b]{3}{*}{ Item } & \multicolumn{8}{|c|}{ Muscle $^{2}$} & \multirow[b]{3}{*}{ SEM } & \multirow{2}{*}{\multicolumn{3}{|c|}{$P$-value }} \\
\hline & \multicolumn{2}{|c|}{ DT } & \multicolumn{2}{|c|}{ TLH } & \multicolumn{2}{|c|}{ TFL } & \multicolumn{2}{|c|}{ ST } & & & & \\
\hline & $\mathrm{CON}$ & $\mathrm{RAC}+$ & $\mathrm{CON}$ & $\mathrm{RAC}+$ & $\mathrm{CON}$ & $\mathrm{RAC}+$ & $\mathrm{CON}$ & $\mathrm{RAC}+$ & & $\mathrm{TRT}^{3}$ & Muscle & TRT $\times$ muscle \\
\hline \multicolumn{13}{|l|}{ Fiber type, $\%$} \\
\hline Type I & 20.41 & 16.94 & 15.19 & 15.57 & 11.55 & 6.82 & 6.70 & 6.42 & 1.76 & 0.07 & $<0.01$ & 0.30 \\
\hline Type IIA & 27.37 & 27.70 & 25.60 & 28.05 & 28.56 & 22.08 & 21.56 & 23.29 & 2.46 & 0.77 & 0.07 & 0.10 \\
\hline Type IIX & 21.79 & 20.97 & 18.29 & 19.04 & 17.06 & 19.16 & 18.35 & 14.71 & 5.26 & 0.77 & 0.10 & 0.50 \\
\hline Type IIB & 30.86 & 34.48 & 41.02 & 37.43 & 42.92 & 50.03 & 53.48 & 55.67 & 3.53 & 0.13 & $<0.01$ & 0.12 \\
\hline \multicolumn{13}{|c|}{ Cross-sectional area, $\mu \mathrm{m}^{2}$} \\
\hline Type I & 2,771 & 3,601 & 3,118 & 3,445 & 2,525 & 2,683 & 3,876 & 4,426 & 508 & 0.07 & $<0.01$ & 0.55 \\
\hline Type IIA & 3,287 & 4,240 & 3,659 & 4,285 & 3,474 & 3,545 & 4,334 & 5,085 & 380 & 0.03 & $<0.01$ & 0.36 \\
\hline Type IIX & 4,261 & 5,093 & 4,977 & 5,410 & 5,024 & 4,891 & 5,955 & 6,624 & 591 & 0.17 & $<0.01$ & 0.50 \\
\hline Type IIB & 4,747 & 5,480 & 5,225 & 5,672 & 5,161 & 5,265 & 4,722 & 5,538 & 535 & 0.11 & 0.67 & 0.63 \\
\hline \multicolumn{13}{|c|}{$\mathrm{SDH}$ intensity, ${ }^{4} \mathrm{AU}$} \\
\hline Type I & 45.50 & 40.07 & 42.07 & 36.56 & 38.26 & 39.27 & 54.83 & 50.49 & 9.52 & 0.21 & $<0.01$ & 0.64 \\
\hline Type IIA & 45.62 & 45.40 & 46.97 & 43.91 & 42.68 & 44.71 & 56.79 & 58.87 & 10.16 & 0.93 & $<0.01$ & 0.78 \\
\hline Type IIX & 66.90 & 60.90 & 64.45 & 57.95 & 61.64 & 61.46 & 73.39 & 73.00 & 15.85 & 0.22 & $<0.01$ & 0.65 \\
\hline Type IIB & 78.17 & 75.30 & 82.35 & 70.58 & 75.61 & 77.80 & 82.26 & 81.14 & 20.75 & 0.27 & 0.35 & 0.21 \\
\hline \multicolumn{13}{|c|}{ Capillary density } \\
\hline Ratio $^{5}$ & 1.44 & 1.88 & 1.50 & 2.04 & 1.16 & 1.60 & 1.50 & 2.21 & 0.29 & 0.03 & 0.17 & 0.92 \\
\hline
\end{tabular}

${ }^{1} 10 \mathrm{mg} / \mathrm{kg}$ of ractopamine $\mathrm{HCl}$ (Paylean; Elanco Animal Health, Greenfield, IN; fed during the final $35 \mathrm{~d}$ of feeding).

${ }^{2} \mathrm{DT}=$ deltoideus; $\mathrm{TLH}=$ triceps brachii lateral head; TFL = tensor fasciae latae; $\mathrm{ST}=$ semitendinosus.

${ }^{3} \mathrm{TRT}=$ treatment.

${ }^{4} \mathrm{SDH}=$ succinate dehydrogenase: $0=$ most intense staining and $250=$ least intense staining. $\mathrm{AU}=$ arbitrary units.

${ }^{5}$ Capillary ratio was determined by dividing the total number of capillaries by the total number of muscle fibers

movement; the performance test stimulated elevated lactate production, most likely from muscles; and muscles were becoming damaged as indicated by glutamate and glutamine trends. When pigs are subjected to simulated transportation courses, blood glucose and lactate levels rise (James et al., 2013; Peterson et al., 2015; Puls et al., 2015). Additionally, Weiss et al. (1974) found that after 5 min of increased physical activity, both plasma glucose and plasma lactate were increased. Similar to the current study, Hackl et al. (2009) reported a 13\% decrease in glutamine and a $68 \%$ increase in glutamate after an intense bout of exercise in trotting horses. The present circulating plasma metabolite data suggest that all barrows reached a similar state of exhaustion congruent with intense activity and overall accumulation of these metabolites were not affected by dietary RAC. These findings would indicate that indirect measures of exhaustion through blood metabolite measurement are not useful when subjecting animals to protocols not based on common time or distance traveled but stimulating extreme levels of fatigue.

\section{Electromyography}

To date, no studies exist that use the current exhaustion model and EMG technology in pigs fed RAC diets. Electromyography sensors were attached to 4 muscles important to ambulatory movement in pigs: the DT and TLH of the forelimb and the TFL and ST of the hind limb. The current study did not examine EMG measures across the duration of the performance test but analyzed the last $15 \mathrm{~s}$ of movement for each barrow before subjective exhaustion occurred to identify the specific physiological mechanisms responsible for exhaustion. In the cascade of events that are responsible for muscle contraction, MdPF measures action potential conduction velocity or the velocity at which the motor unit action potential travels along muscle fibers during contraction (Soares et al., 2015). Typically, as a muscle fatigues, MdPF decreases (Hagg, 1992). In humans, during repeated resistance training, Jenkins et al. (2015) reported decreased frequency in leg muscles with increasing repetition. Cockram et al. (2012) reported sheep displayed a reduction in MdPF in the ST during prolonged slow treadmill walking but the TFL was unaffected. In the current study, end-point values were not different between muscles or treatment. These findings indicate this segment of the muscle contraction process was not responsible for the onset of exhaustion.

Electromyography measurement of RMS serves as an indicator of muscle fiber recruitment (number of active muscle fibers) or motor neuron firing rate. Although MdPF was unaffected by treatment, end-point RMS 
values indicate why RAC+ barrows became exhausted faster than CON barrows. There was a tendency for $\mathrm{RAC}+$ barrows to have reduced end-point RMS values in the ST, thus indicating an increased loss in muscle fibers. Possibly in an effort to compensate for the loss of ST fibers, end-point RMS values in the TFL muscle of RAC+ barrows tended to increase, or the TFL recruited more fibers. In human performance literature, RMS values in the vastus lateralis decreased during repeated sprints designed to induce fatigue (Mendez-Villanueva et al., 2008). Decreased muscle fiber activation, indicated by RMS values, during repeated physical activity in humans were also reported by Kinugasa et al. (2004) and Racinais et al. (2007). Therefore, of the muscles analyzed, it is possible the reduction of ambulatory movement in pigs fed a RAC diet may be due to a reduction in muscle fiber recruitment in the ST, a muscle that is important in extending the hip, stifle, and hock and flexes the stifle when the leg is lifted (Jones et al., 2005).

\section{Fiber Type, Succinate Dehydrogenase, and Capillary Density}

Over all muscles and barrows, there were 13\% type I, 24\% type IIA, 19\% type IIX, and 44\% type IIB fibers. This distribution is slightly different than those reported by Lefaucheur et al. (2002) and Paulk et al. (2014), who reported distributions of $8 \%$ type I, 11 to 14\% type IIA, 25 to $32 \%$ type IIX, and 46 to $50 \%$ type IIB fibers in swine LM muscles. The small difference between studies could be due to the different muscles analyzed. The previous studies analyzed a support muscle whereas the current study examined main locomotive muscles. The histochemical and immunohistochemical analysis in this study would indicate there are differences in metabolism between the ST and the other muscles. The ST had the least type I and most type IIB fibers, the latter of which are highly glycolytic and are most susceptible to fatigue (Pette and Staron, 2001). Succinate dehydrogenase is found in the inner membrane of the mitochondria, where the ability to produce ATP is dependent on oxidative phosphorylation (Kern et al., 1999); therefore, a cell that is more oxidative in nature possesses more SDH. The ST had less SDH in type I, IIA, and IIX fibers compared with all other muscles, indicating a reduced oxidative capacity. Finally, the ST contained larger type I, IIA, and IIX fibers than the other muscles. Muscles with larger fibers possess a reduced $\mathrm{VO}_{2}$ max, the maximum oxygen consumption of the fiber, and muscles with reduced $\mathrm{VO}_{2}$ max are more easily fatigable (van Wessel et al., 2010). These findings provide further evidence to the importance of the ST in contributing to onset of exhaustion.

The fiber type and CSA response in LM of pigs supplemented RAC is well documented. Sainz et al.
(1993) reported no difference in fiber percentage but increases in CSA of type II fibers when pigs were fed $20 \mathrm{mg} / \mathrm{kg}$ RAC for various time periods. Depreux et al. (2002) showed no difference in type I, decreased type IIA and IIX, and increased type IIB fiber percentages in pigs fed $60 \mathrm{mg} / \mathrm{kg}$ RAC for $42 \mathrm{~d}$. When pigs were fed $10 \mathrm{mg} / \mathrm{kg}$ RAC for $35 \mathrm{~d}$, the percentage of type IIB fibers increased at the expense of type IIX fibers (Paulk et al., 2014) and Burnett et al. (2016) reported increased CSA of type IIA and IIX fibers. Aalhus et al. (1992) found fiber type and fiber size consistently were affected by dietary RAC across multiple muscles. Over all muscles in the current study, RAC+ barrows tended to have $15 \%$ less type I fibers and on average $15 \%$ larger type I and IIA fibers. These changes could possibly explain the increased rate at which RAC + barrows became exhausted. As stated above, shifting fibers within muscles away from oxidative metabolism and increasing size, which could contribute to a reduced $\mathrm{VO}_{2}$ max, should make muscles more easily fatigable.

Capillaries allow for blood flow to and from the muscle, which is important for exchange of nutrients and waste (Aberle et al., 2003). Petersen et al. (1998) and Velotto et al. (2010) both reported capillary-to-fiber ratios that ranged from 0.90 to 1.50 for the psoas major, rhomboideus, and longissimus dorsi muscles. The current study found ratios that ranged from 1.44 to 2.21 for all locomotor muscles examined. The RAC + barrows had increased capillary density compared with CON barrows. There is evidence that $\beta$-agonists increase blood flow to muscles, which results in hypertrophy (for review, see Mersmann, 1998). Increased capillary density could be a mechanism by which the body is compensating for the increased size of RAC + barrow muscle fibers. Typically, there is increased oxygen delivery to oxidative fibers, which contain more capillaries than glycolytic fibers (Andersen, 1975; Hudlicka, 1985), meaning that muscles with highly fatigue resistant properties have increased capillary density. Therefore, the result of RAC+ barrows reaching exhaustion quicker than $\mathrm{CON}$ barrows is contrary to what would be expected for a muscle that has elevated capillary density. This could be due to mitochondria of the muscle cells in RAC + barrows not being equipped to utilize the amount of oxygen delivered to muscle cells, as indicated by SDH staining. The current study is the first of its kind to examine the effects of a $\beta$-agonist on the SDH intensity within muscle cells of livestock. Lynch et al. (1996) and Suzuki et al. (1997) reported that mice and rats fed a $\beta$-adrenergic agonist displayed decreased SDH concentrations in various muscles. Muscle cells become more fatigue resistant with increased SDH concentrations (Kugelberg and Lindegren, 1979; Martin and Edgerton, 1992). Dietary RAC did not affect the amount of SDH present in all fiber types de- 
spite changes in type I percentage and the size of type I and IIA fibers. The lack of a change in the oxidative capacity in the type I and IIA fibers, in the presence of increased CSA, may contribute to early onset of exhaustion in RAC+ barrows.

\section{Conclusion}

Feeding barrows a formulated diet containing $10 \mathrm{mg} / \mathrm{kg}$ RAC for $32 \mathrm{~d}$ decreased time and distance walked until exhaustion during a performance test. Electromyography analysis indicated that this occurred due to a loss of active muscle fibers in the ST, whereas the TFL attempted to compensate for these losses by increasing fiber recruitment. The ST possesses the physiology to become exhausted earlier because it contains larger fibers that are less oxidative in metabolism. Although dietary inclusion of RAC increased the density of capillaries present in all muscles, SDH presence was not altered as type I and IIA fibers increased in CSA. Therefore, the increases in the CSA of these fibers with no change in oxidative capacity may contribute to early onset exhaustion of barrows fed a RAC diet. Overall, EMG technology can be a valuable tool in directly measuring the muscle fiber recruitment patterns responsible for onset of muscle exhaustion in pigs.

\section{LITERATURE CITED}

Aalhus, J. L., A. L. Schaefer, A. C. Murray, and S. D. M. Jones. 1992. The effect of ractopamine on myofibre distribution and morphology and their relation to meat quality in swine. Meat Sci. 31:397-409. doi:10.1016/0309-1740(92)90023-W

Aberle, E. D., J. C. Forrest, D. E. Gerrard, and E. W. Mills. 2003. Principles of meat science. 4th ed. Kendall/Hunt Publishing Co., Dubuque, IA.

Andersen, P. 1975. Capillary density in skeletal muscle of man. Acta Physiol. Scand. 95:203-205. doi:10.1111/j.1748-1716.1975. tb10043.x

Apple, J. K., C. V. Maxwell, B. R. Kutz, L. K. Rakes, J. T. Sawyer, Z. B. Johnson, T. A. Armstrong, S. N. Carr, and P. D. Matzat. 2008. Interactive effect of ractopamine and dietary fat source on port quality characteristics of fresh pork chops during simulated retail display. J. Anim. Sci. 86:2711-2722. doi:10.2527/ jas.2007-0327

Armstrong, T. A., D. J. Ivers, J. R. Wagner, D. B. Anderson, W. C. Weldon, and E. P. Berg. 2004. The effect of dietary ractopamine concentration and duration of feeding on growth performance, carcass characteristics, and meat quality of finishing pigs. J. Anim. Sci. 82:3245-3253.

Bohrer, B. M., J. M. Kyle, K. L. Little, H. N. Zerby, and D. D. Boler. 2013. The effects of a step-up program on growth performance and low-sodium ham characteristics of purebred Berkshire pigs. J. Anim. Sci. 91:5535-5543. doi:10.2527/jas.2013-6854

Broxterman, R. M., C. J. Ade, S. L. Wilcox, S. J. Schlup, J. C. Craig, and T. J. Barstow. 2014. Influence of duty cycle on the power-duration relationship: Observations and potential mechanisms. Respir. Physiol. Neurobiol. 192:102-111. doi:10.1016/j. resp.2013.11.010
Burnett, D. D., C. B. Paulk, M. D. Tokach, J. L. Nelssen, M. A. Vaughn, K. J. Phelps, S. S. Dritz, J. M. DeRouchey, R. D. Goodband, K. D. Haydon, and J. M. Gonzalez. 2016. Effects of added zinc on skeletal muscle morphometrics and gene expression of finishing pigs fed ractopamine-HCl. Anim. Biotechnol. 27:17-29. doi:10. 1080/10495398.2015.1069301

Carr, S. N., D. J. Ivers, D. B. Anderson, D. J. Jones, D. H. Mowrey, M. B. England, J. Killefer, P. J. Rincker, and F. K. McKeith. 2005. The effects of ractopamine hydrochloride on lean carcass yields and pork quality characteristics. J. Anim. Sci. 83:2886-2893.

Cockram, M. S., E. Murphy, S. Ringrose, F. Wemelsfelder, H. M. Miedema, and D. A. Sandercock. 2012. Behavioral and physiological measures following treadmill exercise as potential indicators to evaluate fatigue in sheep. Animal 6:1491-1502. doi:10.1017/S1751731112000638

Crome, P. K., F. K. McKeith, T. R. Carr, D. J. Jones, D. H. Mowrey, and J. E. Cannon. 1996. Effect of ractopamine on growth performance, carcass composition, and cutting yields of pigs slaughtered at 107 and 125 kilograms. J. Anim. Sci. 74:709-716.

Depreux, F. F. S., A. L. Grant, D. B. Anderson, and D. E. Gerrard. 2002. Paylean alters myosin heavy chain isoform content in pig muscle. J. Anim. Sci. 80:1888-1894.

Girsch, W., M. Bijak, G. Heger, R. Koller, H. Lanmüller, W. Mayr, H. Tjoma, and U. Losert. 1995. Monitoring of FES-induced muscle activity by continuous EMG-recording. Int. J. Artif. Organs 18:340-344.

Hackl, S., R. van den Hoven, M. Zickl, J. Spona, and J. Zentek. 2009. The effects of short intense exercise on plasma free amino acids in Standardbred trotters. J. Anim. Physiol. Anim. Nutr. 93:165173. doi:10.1111/j.1439-0396.2007.00801.x

Hagg, G. M. 1992. Interpretation of EMG spectral alterations and alteration indexes at sustained contraction. J. Appl. Physiol. 73:1211-1217.

Hamilton, D. N., M. Ellis, T. M. Bertol, and K. D. Miller. 2004. Effect of handling intensity and live weight on blood acid-base status in finishing pigs. J. Anim. Sci. 82:2405-2409.

Hudlicka, O. 1985. Regulation of muscle blood flow. Clin. Physiol. 5:201-229.

Hunter, L., M. K. Seeley, J. T. Hopkins, C. Carr, and J. J. Franson. 2014. EMG activity during positive-pressure treadmill running. J. Electromyogr. Kinesiol. 24:348-352. doi:10.1016/j.jelekin.2014.01.009

James, B. W., M. D. Tokach, R. D. Goodband, J. L. Nelssen, S. S. Dritz, K. Q. Owen, J. C. Woodworth, and R. C. Sulabo. 2013. Effects of dietary L-carnitine and ractopamine $\mathrm{HCl}$ on the metabolic responses to handling in finishing pigs. J. Anim. Sci. 91:4426-4439. doi:10.2527/jas.2011-4411

Jenkins, N. D. M., T. J. Housh, H. C. Bergstrom, K. C. Cochrane, E. C. Hill, C. M. Smith, G. O. Johnson, R. J. Schmidt, and J. T. Cramer. 2015. Muscle activation during three sets to failure at 80 vs. $30 \% 1$ RM resistance exercise. Eur. J. Appl. Physiol. 115:2335-2347. doi:10.1007/s00421-015-3214-9

Jones, S. J., C. R. Calkins, B. Carpenter, B. L. Gwartney, and D. D. Johnson. 2005. Bovine myology and muscle profiling. National Cattleman's Beef Assoc., Centennial, CO.

Keast, D., D. Arstein, W. Harper, R. W. Fry, and A. R. Morton. 1995. Depression of plasma glutamine concentration after exercise stress and its possible influence on the immune system. Med. J. Aust. 162:15-18.

Kern, P. A., R. B. Simsolo, and M. Fournier. 1999. Effect of weight loss on muscle fiber type, fiber size capillarity, and succinate dehydrogenase activity in humans. J. Clin. Endocrinol. Metab. 84:4185-4190. 
Kinugasa, R., H. Akima, A. Ota, A. Ohta, K. Sugiura, and S. Kuno. 2004. Short-term creatine supplementation does not improve muscle activation or sprint performance in humans. Eur. J. Appl. Physiol. 91:230-237. doi:10.1007/s00421-003-0970-8

Kjäer, M. 1988. Hepatic glucose production during exercise. Adv. Exp. Med. Biol. 441:117-127. doi:10.1007/978-1-4899-1928$1 \_11$

Kugelberg, E., and B. Lindegren. 1979. Transmission and contraction fatigue of rat motor units in relation to succinate dehydrogenase activity of motor unit fibres. J. Physiol. 288:285-300.

Lee, S. S. M., M. D. Miara, A. S. Arnold, A. A. Biewener, and J. M. Wakeling. 2013. Recruitment of faster motor units is associated with greater rates of fascicle strain and rapid changes in muscle force during location. J. Exp. Biol. 216:198-207. doi:10.1242/ jeb.072637

Lefaucheur, L., P. Ecolan, L. Plantard, and N. Gueguen. 2002. New insights into muscle fiber types in the pig. J. Histochem. Cytochem. 50:719-730. doi:10.1177/002215540205000513

Leibowitz, A., Y. Klin, B. F. Gruenbaum, S. E. Gruenbaum, R. Kuts, M. Dubilet, S. Ohayon, M. Boyko, E. Sheiner, Y. Shapira, and A. Zlotnik. 2012. Effects of strong physical exercise on blood glutamate and its metabolite 2-ketoglutarate levels in healthy volunteers. Acta Neurobiol. Exp. (Warsz.) 72:385-396.

Lynch, G. S., A. Hayes, S. P. Campbell, and D. A. Williams. 1996. Effects of $\beta_{2}$-agonist administration and exercise on contractile activation of skeletal muscle fibers. J. Appl. Physiol. 81:1610 1618.

Main, R. G., S. S. Dritz, M. D. Tokach, R. D. Goodband, J. L. Nelssen, and J. M. DeRouchey. 2009. Effect of ractopamine $\mathrm{HCl}$ dose and treatment period on pig performance in a commercial finishing facility. J. Swine Health Prod. 17:134-139.

Marchant-Forde, J. N., D. C. Lay Jr., E. A. Pajor, B. T. Richert, and A. P. Schinckel. 2003. The effects of ractopamine on the behavior and physiology of finishing pigs. J. Anim. Sci. 81:416-422.

Martin, T. P., and V. R. Edgerton. 1992. Intrafibre distribution of succinate dehydrogenase in cat tibialis anterior motor units. Can. J. Physiol. Pharmacol. 70:970-976. doi:10.1139/y92-133

Mendez-Villanueva, A., P. Hamer, and D. Bishop. 2008. Fatigue in repeated-sprint exercise is related to muscle power factors and reduced neuromuscular activity. Eur. J. Appl. Physiol. 103:411419. doi:10.1007/s00421-008-0723-9

Mersmann, H. J. 1998. Overview of the effects of $\beta$-adrenergic receptor agonists on animal growth including mechanisms of action. J. Anim. Sci. 76:160-172.

Moloney, A., P. Allen, R. Joseph, and V. Tarrant. 1991. Influence of beta-adrenergic agonists and similar compounds on growth. In: A. M. Pearson and T. R. Dutson, editors, Advances in meat research. Elsevier Publishing, New York, NY. p. 455-513.

Murray, M. P., G. B. Spurr, S. B. Sepic, G. M. Gardner, and L. A. Mollinger. 1985. Treadmill vs. floor walking: Kinematics, electromyogram, and heart rate. J. Appl. Physiol. 59:87-91.

National Pork Producers Council (NPPC). 1999. Pork quality standards. NPPC, Des Moines, IA.

NRC. 2012. Nutrient requirements of swine. 11th rev. ed. Natl. Acad. Press, Washington, DC.

Paulk, C. B., D. D. Burnett, M. D. Tokach, J. L. Nelssen, S. S. Dritz, J. M. DeRouchey, R. D. Goodband, G. M. Hill, K. D. Haydon, and J. M. Gonzalez. 2015. Effect of added zinc in diets with ractopamine hydrochloride on growth performance, carcass characteristics, and ileal mucosal inflammation mRNA expression of finishing pigs. J. Anim. Sci. 93:185-196. doi:10.2527/ jas.2014-8286
Paulk, C. B., M. D. Tokach, J. L. Nelson, D. D. Burnett, M. A. Vaughn, K. J. Phelps, S. S. Dritz, J. M. DeRouchey, R. D. Goodband, J. C. Woodworth, T. A. Houser, K. D. Haydon, and J. M. Gonzalez. 2014. Effect of dietary zinc and ractopamine hydrochloride on pork chop muscle fiber type. J. Anim. Sci. 92:2325-2335. doi:10.2527/jas.2013-7318

Petersen, J. S., P. Henckel, N. Oksbjerg, and M. T. Sorensen. 1998. Adaptations in muscle fibre characteristics induced by physical activity in pigs. Anim. Sci. 66:733-740. doi:10.1017/ S1357729800009310

Peterson, C. M., C. M. Pilcher, H. M. Rothe, J. N. Marchant-Forde, M. J. Ritter, S. N. Carr, C. L. Puls, and M. Ellis. 2015. Effect of feeding ractopamine hydrochloride on growth performance and responses to handling and transport in heavy-weight pigs. J. Anim. Sci. 93:1239-1249. doi:10.2527/jas.2014-8303

Pette, D., and R. S. Staron. 2001. Transitions of muscle fiber phenotypic profiles. Histochem. Cell Biol. 115:359-372.

Poole, D. C., S. A. Ward, G. W. Gardner, and B. J. Whipp. 1988. Metabolic and respiratory profile of the upper limit for prolonged exercise in man. Ergonomics 31:1265-1279. doi:10.1080/00140138808966766

Puls, C. L., W. E. Trout, M. J. Ritter, F. K. McKeith, S. N. Carr, and M. Ellis. 2015. Impact of ractopamine hydrochloride on growth performance, carcass and pork quality characteristics, and response to handling and transport in finishing pigs. J. Anim. Sci. 93:1229-1238. doi:10.2527/jas.2014-8097

Racinais, S., D. Bishop, R. Denis, G. Lattier, A. Mendez-Villaneuva, and S. Perrey. 2007. Muscle deoxygenation and neural drive to the muscle during repeated sprint cycling. Med. Sci. Sports Exerc. 39:268-274. doi:10.1249/01.mss.0000251775.46460.cb

Rajapaksha, E., and C. B. Tucker. 2014. How do cattle respond to sloped floors? An investigation using behavior and electromyograms. J. Dairy Sci. 97:2808-2815. doi:10.3168/jds.2013-7435

Ritter, M. J., M. Ellis, N. L. Berry, S. E. Curtis, L. Anil, E. Berg, M. Benjamin, D. Butler, C. Dewey, B. Driessen, P. DuBois, J. D. Hill, J. N. Marchant-Forde, P. Matzat, J. McGlone, P. Mormede, T. Moyer, K. Pfalzgraf, J. Salak-Johnson, M. Siemens, J. Sterle, C. Stull, R. Whiting, B. Wolter, S. R. Niekamp, and A. K. Johnson. 2009. Review: Transport losses in market weight pigs: I. A review of definitions, incidence, and economic impact. Prof. Anim. Sci. 25:404- 414.

Ritter, M. J., M. Ellis, J. Brinkmann, J. M. DeDecker, K. K. Keffaber, M. E. Kocher, B. A. Peterson, J. M. Schlipf, and B. F. Wolter. 2006. Effect of floor space during transport of market-weight pigs on the incidence of transport losses at the packing plant and the relationships between transport conditions and losses. J. Anim. Sci. 84:2856-2864. doi:10.2527/jas.2005-577

Robert, C., J. P. Valette, and J. M. Denoix. 2000. The effects of treadmill inclination and speed on the activity of two hindlimb muscles in the trotting horse. Equine Vet. J. 32:312-317. doi:10.2746/042516400777032246

Rocha, L. M., A. M. Bridi, A. Foury, P. Mormède, A. V. Weschenfelder, N. D. Devillers, W. Bertoloni, and L. Faucitano. 2013. Effects of ractopamine administration and castration method on the response to preslaughter stress and carcass and meat quality in pigs of two Piétrain genotypes. J. Anim. Sci. 91:3965-3977. doi:10.2527/jas.2012-6058

Sainz, R. D., Y. S. Kim, F. R. Dunshea, and R. G. Campbell. 1993. Effects of ractopamine in pig muscles: Histology, calpains and $\beta$-adrenergic receptors. Aust. J. Agric. Res. 44:1441-1448. doi:10.1071/AR9931441 
Soares, F. A., J. L. A. Carvalho, C. J. Miosso, M. M. de Andrade, and A. F. da Rocha. 2015. Motor unit action potential conduction velocity estimated from surface electromyographic signals using image processing techniques. Biomed. Eng. Online 14:84. doi:10.1186/s12938-015-0079-4

Stites, C. R., F. K. McKeith, S. D. Singh, P. J. Bechtel, D. H. Mowrey, and D. J. Jones. 1991. The effect of ractopamine hydrochloride on the carcass cutting yields of finishing swine. J. Anim. Sci. 69:3094-3101.

Suzuki, J., M. Gao, Z. Xie, and T. Koyama. 1997. Effects of the $\beta 2-$ adrenergic agonist clenbuterol on capillary geometry in cardiac and skeletal muscles in young and middle aged rats. Acta Physiol. Scand. 161:317-326. doi:10.1046/j.1365-201X.1997.00236.x

Svedahl, K., and B. R. MacIntosh. 2003. Anaerobic threshold: The concept and methods of measurement. Can. J. Appl. Physiol. 28:299-323. doi:10.1139/h03-023 van Wessel, T., A. de Haan, W. J. van der Laarse, and R. T. Jaspers. 2010. The muscle fiber type-fiber size paradox: Hypertrophy or oxidative metabolism? Eur. J. Phys. 110:665-694.

Velotto, S., C. Vitale, T. Stasi, and A. Crasto. 2010. New insights into muscle fibre types in Casertana pig. Acta Vet. (Brno) 79:169176. doi:10.2754/avb201079020169

Walsh, N. P., A. K. Blannin, P. J. Robson, and M. Gleeson. 1998. Glutamine, exercise, and immune function. Sports Med. 26:177-191. doi:10.2165/00007256-199826030-00004

Watkins, L. E., D. J. Jones, D. H. Mowrey, D. B. Anderson, and E. L. Veenhuizen. 1990. The effect of various levels of ractopamine hydrochloride on the performance and carcass characteristics of finishing swine. J. Anim. Sci. 68:3588-3595.

Weiss, G. M., D. G. Topel, D. G. Siers, and R. C. Ewan. 1974. Influence of adrenergic blockage upon some endocrine and metabolic parameters in a stress-susceptible and a fat strain of swine. J. Anim. Sci. 38:591-597. 